\title{
Examining the Regulatory Value of Multi-route Mammalian Acułe Systemic Toxicity Studies
}

\author{
Troy Seidle ${ }^{1}$, Pilar Prieto ${ }^{2}$ and Anna Bulgheroni ${ }^{2}$ \\ ${ }^{1}$ Humane Society International, Research \& Toxicology Department, Brussels, Belgium and CAAT-Europe, University of \\ Konstanz, Germany; ${ }^{2}$ In-Vitro Methods Unit, European Centre for the Validation of Alternative Methods, Institute for Health \\ and Consumer Protection, European Commission Joint Research Centre, Ispra, Varese, Italy
}

\begin{abstract}
Summary
Regulatory information requirements for pesticides call for submission of acute systemic toxicity data for up to three different exposure routes (oral, dermal, inhalation) for both active ingredients and formulated products. Similar multi-route testing is required in the European Union and elsewhere for industrial chemicals. To determine the value of acute toxicity testing by more than one route, oral-dermal and oralinhalation concordances among regulatory classifications were examined for large data sets of chemicals and pesticide active ingredients. Across all sectors examined, oral acute toxicity classifications for pure active substances were more severe than those derived from dermal data in more than $98 \%$ of cases, which calls into question the value of routine dermal route testing for acute toxicity. Oral classifications were equivalent to or more severe than for the inhalation route for $83 \%$ of industrial chemicals and for $48 \%$ of pesticides examined.
\end{abstract}

Keywords: dermal toxicity, intelligent testing, $L D_{50}$, redundancy, regulatory classification

\section{Introduction}

Acute toxicity refers to adverse effects occurring following a single exposure to a substance or following multiple exposures within 24 hours. In the area of regulatory toxicology, acute toxicity studies are the longest standing class of toxicity test, dating back to the "lethal dose 50 percent" method developed by Trevan (1927). However, the use of lethality as an endpoint has long been a subject of controversy on both ethical/animal welfare and scientific grounds (Balls, 1991; Robinson et al., 2008; Seidle et al., 2010). Pharmaceutical companies have stated that "these studies have limited value in terms of pre-clinical and human safety assessment compared to the substantial adverse effects experienced by some of the animals" (Robinson et al., 2008), and this sector itself has recently moved to discontinue the routine requirement for stand-alone acute toxicity studies (ICH, 2009). Systemic acute toxicity studies nonetheless remain a common feature in a number of regulatory frameworks and voluntary initiatives, such as high production volume (HPV) chemicals programs. Available statistics indicate that more animals have been used in recent years in assessment of this endpoint than in any other single area of toxicology (EC, 2007).

In certain sectors, regulatory information requirements prescribe testing for acute toxicity by up to three different exposure routes (oral, dermal, inhalation), and in some cases, for both individual substances/ingredients and formulated products/articles. This generally is the case for agricultural and plant protection chemicals and biocidal products (collectively referred to as "pesticides") due to their intended biological activity and toxic mode of action, as well as the potential for human exposure via multiple routes (e.g., oral ingestion of residues on food; potential dermal and/or inhalation exposure during the application process, and in other occupational scenarios). Requirements for industrial chemicals are more variable from country to country but in certain cases may also prescribe acute systemic toxicity testing by more than one exposure route. For example, the Registration, Evaluation, Authorisation and Restriction of Chemicals $(\mathrm{REACH})$ regulation in the European Union (EU) requires single-route acute toxicity data for all substances manufactured or imported in volumes of more than one metric ton per annum (tpa), and data for a second route for substances in the $\geq 10$ tpa band (OJ, 2007). A detailed review of regulatory requirements and other drivers for acute toxicity test data across industry sectors and major international markets has been published elsewhere (Seidle et al., 2010).

A key finding of the aforementioned review is that the principal use of acute toxicity data is to support regulatory classification and hazard labeling decisions (although it is recognized

Received January 13, 2011; accepted in revised form March 25, 2011. 
that these data can also be used to derive safe use threshold levels, e.g., Derived No Effect Level (DNEL) or Acute Exposure Guideline Level (AEGL)). Frameworks for classification and labeling differ somewhat among countries/regions, and sometimes among authorities within the same country. The Globally Harmonized System of Classification and Labeling of Chemicals (GHS) was developed under the auspices of the United Nations (UN, 2007) to promote increased regulatory consistency and efficiency among countries and sectors. Figure 1 illustrates the different hazard class cut-offs for acute oral toxicity between the
GHS and its most common variants in use in Australia, Canada, and the EU (OJ, 2008), as well as the former EU scheme under the Dangerous Substances Directive (OJ, 1967), and schemes used by United States agencies charged with worker protection (OSHA, 2009) and the regulation of consumer products (CPSC, 1973) and pesticides (EPA, 2004). A key difference among these schemes is the prescribed limit dose (i.e., $2,000 \mathrm{mg} / \mathrm{kg}$ or $5,000 \mathrm{mg} / \mathrm{kg}$ ), beyond which a substance is not required to bear a hazard label for acute toxicity. The GHS designates testing beyond $2000 \mathrm{mg} / \mathrm{kg}$ as optional and discouraged on animal

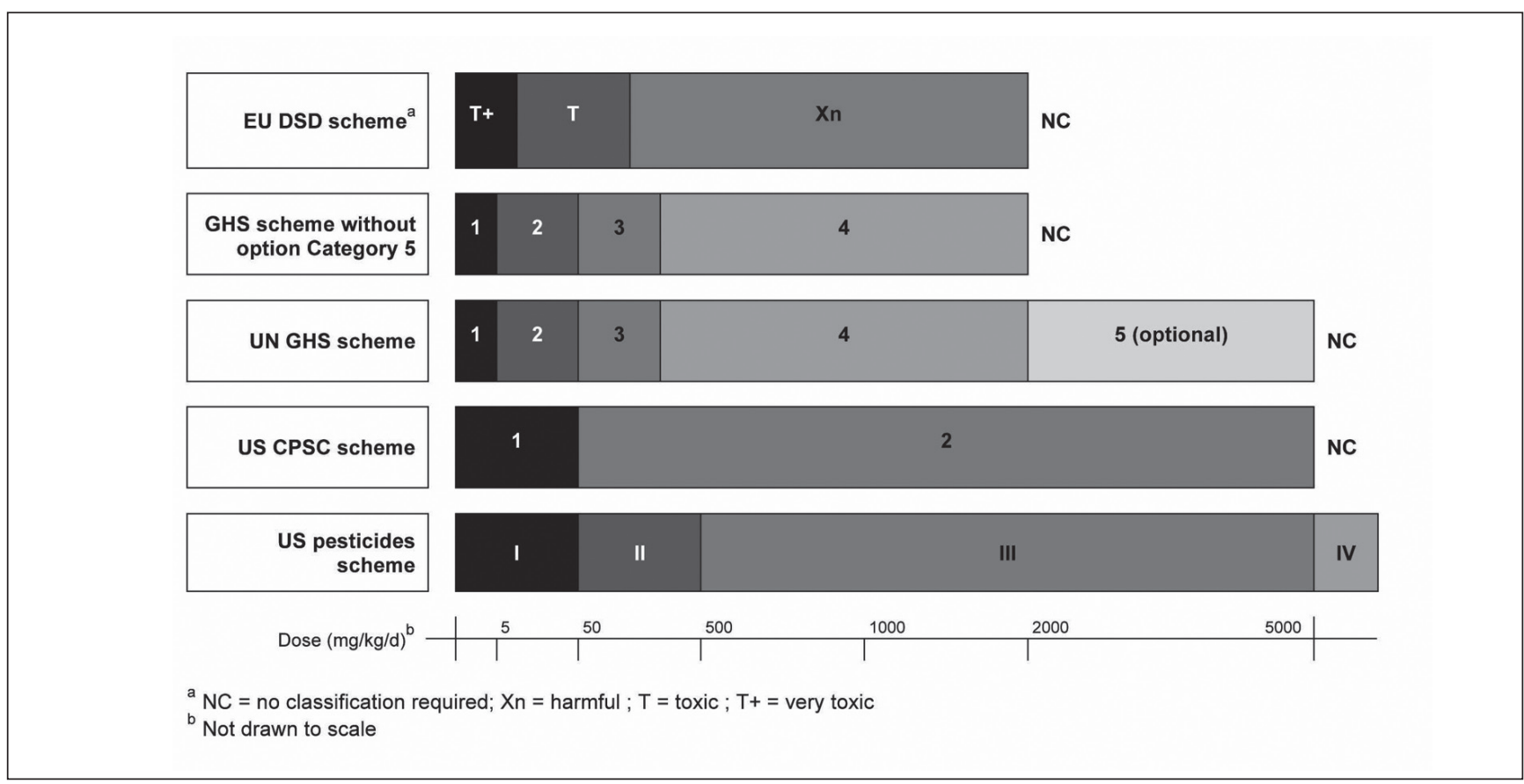

Fig. 1: Comparison of hazard classification schemes for acute oral toxicity

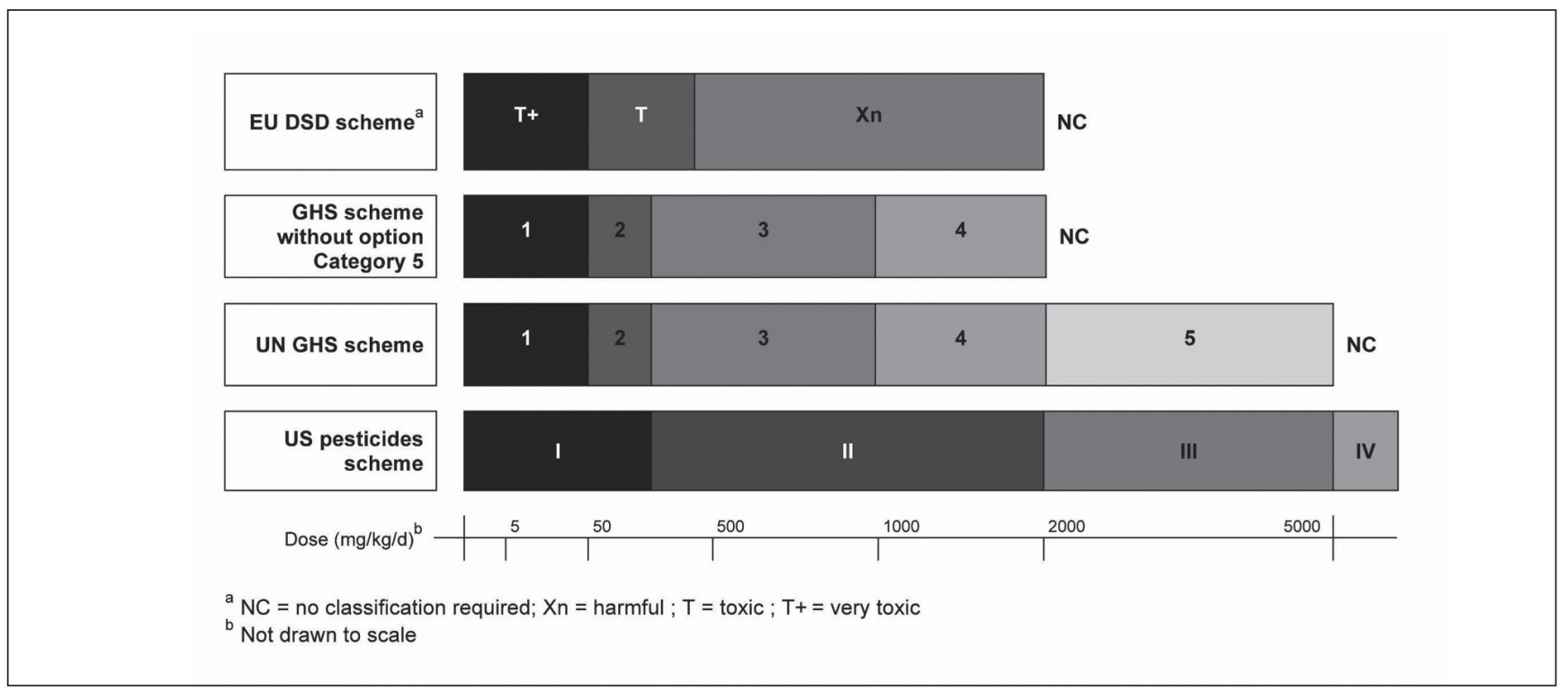

Fig. 2: Comparison of hazard classification schemes for acute dermal toxicity 


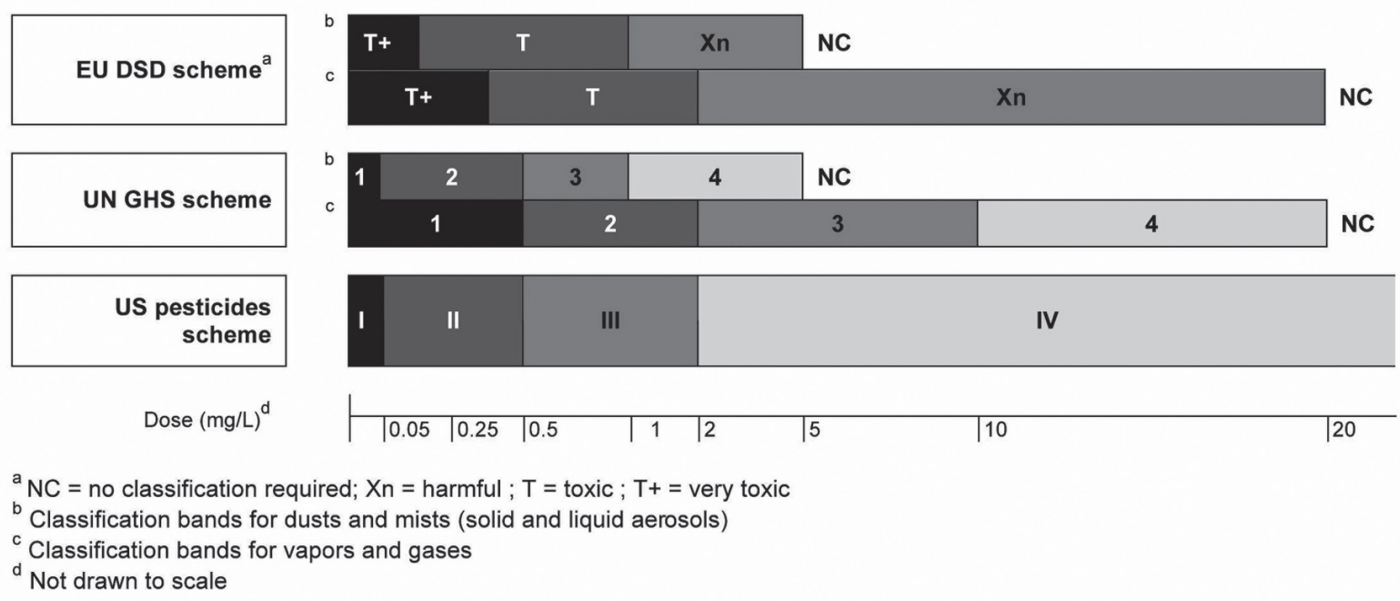

Fig. 3: Comparison of hazard classification schemes for acute inhalation toxicity

welfare grounds (UN, 2007), and the US Occupational Safety and Health Administration (OSHA, 2009) adds that exposures of this magnitude are not likely to be encountered in the occupational setting. For these reasons, countries adopting the GHS are for the most part adopting a $2,000 \mathrm{mg} / \mathrm{kg}$ limit dose for acute oral toxicity. Figures 2 and 3 compare selected classification schemes for acute dermal and inhalation toxicity.

Notwithstanding differences among national and sectorspecific classification systems, it is common to use the lowest available oral or dermal lethal dose (LD50) or inhalation lethal concentration $\left(\mathrm{LC}_{50}\right)$ value to assign a substance or article to a hazard category (OJ, 2008), and label warnings normally reflect the most severe hazard category (UN, 2007; OSHA, 2009). Thus, if it were possible to identify an exposure route that is consistently more or less sensitive than another and is relevant to a particular exposure scenario, multi-route animal testing would not be necessary. The " 3 Rs" principle of replacement, reduction, and refinement of animal use (Russell and Burch, 1959) is a longstanding tenet of sound science, and it seems especially apt in the case of toxicity studies that involve not only death as a primary endpoint in most cases but also testing of the same substance using multiple routes of exposure and/or species. In some parts of the world, the minimization of animal testing is a legal requirement, as exemplified by Article 7.2 of EU Directive 86/609/EEC for the protection of animals used for experimental and other scientific purposes (OJ, 1986), and Article 13 of REACH, which specifies that hazard information shall be generated whenever possible by means other than vertebrate animal tests.

To date, a handful of retrospective reviews of acute oral and dermal toxicity classifications have been reported in the literature. In 1998, investigators from the UK Health and Safety Executive (Indans et al., 1998) presented the results of an analysis of acute toxicity classifications for 438 industrial chemicals notified in the EU for the period 1984 to 1997 . This analysis found that only four of these substances were positively classi- fied for acute dermal toxicity, and for only one of these did the dermal study lead to a more severe classification than the oral study. In 2007, the UK Pesticide Safety Directorate (Thomas and Dewhurst, 2007) examined unpublished acute oral and dermal toxicity data for 195 pesticide active ingredients and 3,111 formulated products, concluding that the dermal study adds little if anything to the database on pesticide active substances, and that a similar result was indicated for formulations. A more recent paper by Creton and colleagues (2010) arrived at the same conclusion following the review of a slightly expanded data set of pesticide active ingredients. This paper builds on the above analyses using a significantly expanded data set of industrial chemicals, as well as pesticide active ingredients from non-EU sources that have not been considered in the aforementioned reviews. We also examine concordances among oral and inhalation route classifications, and consider the impact on our conclusions of the prevalence of positively and negatively classified substances within the database. This publication contributes to the efforts of the Acute Toxicity Task Force of the European Partnership for Alternative Approaches to Animal Testing (EPAA) to identify opportunities for application of the $3 \mathrm{Rs}$ in this area.

\section{Methods}

\subsection{Chemicals dataset}

Data for industrial chemicals were obtained from the EU New Chemicals Database (NCB), a proprietary repository of toxicity information for all substances notified to European authorities since 1981 (i.e., from the entry into force of the sixth amendment to the former EU Dangerous Substances Directive 67/548/ EEC). Substances exempted from notification include pesticides, cosmetics, pharmaceuticals, foodstuffs, radioactive materials, wastes, and substances used in scientific research. When accessed on June 11, 2008, the NCD contained 7,812 notification 
dossiers, representing 4,946 substances notified in Europe since 1981. For the analysis performed in this study, all substances were included that possessed a classification after acute systemic exposure in rats via oral, dermal and/or inhalation routes (3,317 in total). Substances excluded were those for which the $\mathrm{LD} / \mathrm{LC}_{50}$ values reported were not consistent with the classification (e.g., an oral LD50 $>800 \mathrm{mg} / \mathrm{kg}$ being designated "non-classified"). Of the 3,317 substances with acute toxicity data for at least one relevant exposure route, 1,990 (60\%) also were tested by a second route, including 1,737 substances with both oral and dermal data and 81 substances with both oral and inhalation data. Following the application of exclusion criteria, a total of 1,569 substances were used for the oral-dermal concordance assessment, and 71 substances were used for determining oralinhalation concordance.

Regulatory classifications listed in the NCB are based on the now historic EU Dangerous Substances Directive (DSD) scheme (since superseded by EU Regulation 1272/2008 on Classification, Labeling and Packaging of Substances and Mixtures (CLP; OJ, 2008). A decision against converting individual classifications from the four category DSD system to the up to 5-6 category GHS scheme (see Fig. 1-3) was made on the basis that most dermal studies $(97 \%)$ were conducted as limit tests using a $2,000 \mathrm{mg} / \mathrm{kg}$ cutoff, which precludes a direct comparison against oral studies in which dosing up to or beyond $5,000 \mathrm{mg} / \mathrm{kg}$ was performed. As such, substances with oral and dermal LD50 values in excess of $2,000 \mathrm{mg} / \mathrm{kg}$ are considered for the purposes of this analysis as being "non-classified" for acute toxicity.

\subsection{Pesticides dataset}

Data for agrochemical and biocidal active ingredients were obtained through systematic reviews of the following publicly accessible online databases and information repositories maintained by regulatory authorities and intergovernmental bodies: Working Documents of the EC Standing Committee on the Food Chain and Animal Health in view of the inclusion of plant protection active substances in Annex I of Directive 91/414/EEC (EC, 2009a; EC, 2009b) Assessment Reports concerning inclusion of biocidal active substances in Annex I or IA to Directive 98/8/EC; European Food Safety Authority (EFSA, 2009) Draft Assessment Reports for plant protection active substances; US Environmental Protection Agency (EPA, 2009; 2010) Reregistration Eligibility Decision documents and Fact Sheets on new active ingredients; and the International Program on Chemical Safety (IPCS, 2009) INCHEM database. LD/LC50 values were collected if available for at least two of the three relevant exposure routes (oral, dermal, inhalation) using mammalian species and procedures specified in current Organization for Economic Cooperation and Development (OECD, 2009) test guidelines, together with CAS registry number, broad product type (e.g., antimicrobial, insecticide), and physical state descriptor. In the case of regulatory decision documents, only a single value was normally reported for each exposure route, which may reflect a pre-selection by authorities of the (generally lowest) LD/LC50 value from among two or more possible choices. The LD/LC 50 values in the summary documents were taken at face value without attempts at independent confirmation. Given the size of the database, it was considered that any overall conclusions would not be unduly confounded by an occasional error in the production of the summaries. When a range of $\mathrm{LD} / \mathrm{LC}_{50}$ values was cited, the lowest value in the most relevant species (rodent or rabbit) and exposure scenario (e.g., 4-hour inhalation) was selected. In cases where the lowest $\mathrm{LD} / \mathrm{LC}_{50}$ value was obtained using a non-traditional species or one so taxonomically removed from rodents (e.g., non-human primates) as to call into question the validity of a concordance analysis, preference was given to the next lowest $\mathrm{LD} / \mathrm{LC}_{50}$ value in rodents or rabbits. $\mathrm{LD} / \mathrm{LC}_{50}$ values obtained from sources that reported any uncertainty regarding data quality (e.g., inhalation studies in which maximum concentration was not achieved) were excluded from the analysis.

The resulting database is comprised of 429 agrochemical and biocidal active substances representing major product types (antimicrobials and other biocides, biochemicals, fungicides, herbicides, defoliants and plant growth regulators, insecticides, repellants and fumigants, vertebrate control agents, etc.). All $\mathrm{LD} / \mathrm{LC}_{50}$ values were converted to regulatory classifications according to GHS criteria (UN, 2007). In cases where it was unclear whether a test atmosphere consisted of aerosols (solid or liquid), vapors, or a combination of the two, classifications were made according to GHS criteria for aerosols as recommended by Pauluhn et al. (1996). As above, substances with oral and dermal LD50 values in excess of 2,000 mg/kg were considered for the purposes of this analysis as being "non-classified" for acute toxicity. This analysis has purposely excluded substances already examined by Creton et al. (2010). In total, concordance assessments are based on 337 substances that have been tested by both oral and dermal routes, and 348 tested by both oral and inhalation routes. The substances used for the concordance assessments are listed in a supplementary data file on www.altexediton.org.

\section{Results and discussion}

\subsection{Oral-dermal concordance}

The relationship between acute oral and dermal toxicity classifications is summarized in Tables 1 and 2. For chemicals, the overall concordance among oral and dermal LD50 classifications was $93.7 \%$ across 1,569 substances. The oral and dermal route concordance for non-classified substances is $100 \%$. The dermal test resulted in a more severe classification in only one instance $(0.06 \%$ - classified as orally hazardous but dermally toxic), while the oral test yielded positive classifications for 98 substances $(6.2 \%)$ that would have been underclassified by a dermal test alone. Of these, 88 were classed as hazardous, nine as toxic, and one as highly toxic.

For pesticides, the overall oral-dermal concordance was $54 \%$ across 337 substances (Tab. 2). For an additional 148 substances $(43.92 \%)$ the oral test yielded more severe classifications, while the dermal test proved to be more sensitive in six cases (1.78\%). Had the oral LD50 value alone been used as a basis for classification, the pesticides Furfural, Kelevan, Methyli- 
Tab. 1: Concordance among oral and dermal route acute toxicity classifications for industrial chemicals in the EU New Chemicals Database according to the former EU DSD scheme

\begin{tabular}{lccll}
\cline { 2 - 5 } & \multicolumn{2}{c}{ ORAL } & & \\
\hline DERMAL & NC & Xn & T & T+ \\
\hline NC & 1460 & 88 & 9 & 1 \\
\hline $\mathbf{X n}$ & 0 & 10 & 0 & 0 \\
\hline $\mathbf{T}$ & 0 & 1 & 0 & 0 \\
\hline $\mathbf{T}+$ & 0 & 0 & 0 & 0 \\
\hline
\end{tabular}

${ }^{*} \mathrm{NC}=$ no classification required $; \mathrm{Xn}=$ harmful; $\mathrm{T}=$ toxic $; \mathrm{T}+=$ very toxic

Tab. 2: Concordance among oral and dermal route acute toxicity classifications for pesticide active substances according to the GHS (without the optional Category 5)

\begin{tabular}{lccccc}
\cline { 2 - 5 } & \multicolumn{2}{c}{ ORAL } & & & \\
\hline DERMAL & NC & $\mathbf{4}$ & $\mathbf{3}$ & $\mathbf{2}$ & $\mathbf{1}$ \\
\hline NC & 154 & 96 & 32 & 2 & 2 \\
\hline $\mathbf{4}$ & 0 & 6 & 4 & 2 & 0 \\
\hline $\mathbf{3}$ & 1 & 1 & 9 & 6 & 2 \\
\hline $\mathbf{2}$ & 0 & 0 & 3 & 4 & 2 \\
\hline $\mathbf{1}$ & 0 & 0 & 0 & 1 & 10 \\
\hline
\end{tabular}

sothiazolinone, Mirex and Sodium Cyanide would have been underclassified by a single category, while Dowicil ${ }^{\circledR} \mathrm{CTAC}$ (classified dermally as GHS Category 3) would have been unclassified. In the case of Sodium Cyanide (classified orally as GHS Category 2 and dermally as Category 1), the underclassification appears to be GHS-specific, i.e., the oral $\mathrm{LD}_{50}$ of 7.5 $\mathrm{mg} / \mathrm{kg}$ is just above the $5 \mathrm{mg} / \mathrm{kg}$ threshold for inclusion in Category 1 . This discordance would not have occurred under the former DSD scheme or if the US EPA or CPSC schemes had been used (Fig. 1), with their Category 1 thresholds of $25 \mathrm{mg} /$ $\mathrm{kg}$ and $50 \mathrm{mg} / \mathrm{kg}$, respectively. Furthermore, from a hazardlabeling standpoint (relevant for the protection of workers who may be directly exposed to pesticidal active substances), classification in GHS Category 2 as opposed to Category 1 has no impact on label signal word or hazard statement. For Furfural, Kelevan and Methylisothiazolinone (all oral Category 3/dermal Category 2), the signal word "danger" would still be present for all substances, although the hazard statement would be downgraded from "fatal in contact with skin" to "toxic in contact with skin" for a Category 3 classification. For Mirex (oral Category 4/dermal Category 3), both signal word and hazard statement would be downgraded, i.e., from "danger" to "warning" and from "toxic" to "harmful," respectively. Dowicil ${ }^{\circledR}$ CTAC is the only substance that would have been overlooked entirely based on oral data (and a $2,000 \mathrm{mg} / \mathrm{kg}$ limit dose), whereas dermal results would have led to a GHS Category 3 classification and concomitant "danger" and "toxic" label statements, with advice that workers wear chemical-resistant gloves for openpouring of the end-use product (EPA, 2007). The reasons behind the relatively greater sensitivity of the dermal route in this case are not clear at this time, in part due to the lack of dermal penetration studies in the database. Dowicil is considered to be a non-sensitizer based on a guideline study in guinea pigs. In a rabbit dermal irritation study, Dowicil produced only a slight edematous reaction on intact skin, resulting in a "slight irritant" label under the US EPA pesticide classification scheme; however, under the EU CLP scheme, the substance would not be considered a dermal irritant (EPA, 2004; OJ, 2008). The magnitude of the discordance in acute systemic classification results for Dowicil appears, to some extent, also to be classification scheme-specific, i.e., it would not have been as pronounced under the US pesticides scheme.

On the whole, these analyses illustrate the limited value of acute systemic toxicity testing via the dermal route for the purpose of classification and labeling, which is the primary driver for such studies (Seidle et al., 2010), thus calling into question the appropriateness of regulations that continue to require redundant dermal route testing when oral data are already available. The extent to which dermal acute data provide added value for the regulation of formulated preparations/articles is also questionable (Thomas and Dewhurst, 2007) and warrants further investigation.

In the context of chemical regulation in the EU, Table 3 shows the distribution of substances registered in the NCD through June 2008 according to the two levels of information requirements established by REACH for acute systemic toxicity, i.e., annual production volume $\geq 1$ metric ton (Annex VII) and annual production $\geq 10$ metric tons (Annex VIII). Based on their production volume, $25 \%$ of all substances registered

Tab. 3: Distribution of substances listed in the EU New Chemicals Database through June 2008 with acute oral and dermal toxicity data according to REACH tonnage bands

\begin{tabular}{lll}
\cline { 2 - 3 } & $\begin{array}{l}\text { All substances registered } \\
\text { in NCD (June 2008) }\end{array}$ & $\begin{array}{l}\text { Substances with oral and } \\
\text { dermal toxicity data (June 2008) }\end{array}$ \\
\hline $\begin{array}{l}\text { Substances manufactured or imported } \\
\text { in quantities } \geq 1 \text { tpa }\end{array}$ & $25 \%$ & $41 \%$ \\
\hline $\begin{array}{l}\text { Substances manufactured or imported } \\
\text { in quantities } \geq 10 \text { tpa }\end{array}$ & $43 \%$ & $53 \%$ \\
\hline
\end{tabular}


in the NCD fall within the REACH Annex VII requirement for a single-route (usually oral) acute toxicity study, while $43 \%$ of substances fall within the Annex VIII requirement for a second acute study (dermal or inhalation, depending on the nature of the substance and the likely route of human exposure). It is significant to note the relative prevalence of high-tonnage substances in the NCD, as well as the fact that nearly half of these $(47 \%)$ appear not to possess acute toxicity data for more than one exposure route. Thus, a regulatory decision to waive the requirement for an acute dermal study for the estimated 10,000 existing substances that will be subject to REACH Annex VIII data requirements could potentially spare a large number of animals (assuming that dermal testing has not already been carried out, or that an inhalation study is not simply substituted in place of the dermal test; see 3.2. for additional discussion of this point).

With regard to pesticides, we note that at the time of this writing, EU data requirements for agrochemicals are undergoing revision, as are regulations governing the registration of biocides in the EU and antimicrobial pesticides in the US. A review and reconsideration of data requirements for dermal acute systemic toxicity would therefore be both timely and warranted in these regions and elsewhere. In relation to formulated pesticide products, the EU's longstanding acceptance of "classification by calculation", i.e., pursuant to Annex II of the former Directive 1999/45/EC, which has recently been replaced by Regulation (EC) No 1272/2008, could obviate the conduct of redundant in vivo testing of formulations comprised of well characterized active substances and other ingredients (OJ, 1999; 2008).

\subsection{Oral-inhalation concordance}

The relationship between acute oral and inhalation toxicity classifications is summarized in Tables 4 and 5. For chemicals, the overall concordance among oral $\mathrm{LD}_{50}$ and inhalation $\mathrm{LC}_{50}$ classifications was $71.8 \%$ across 71 substances. The oral test resulted in a more severe classification in eight cases $(11.3 \%$, classified as orally hazardous but unclassified by the inhalation route), while the inhalation test yielded positive classifications for nine substances $(6.2 \%)$ that would have been unclassified based on oral findings, and a further three substances (4.2\%) that would have been underclassified by one or more DSD categories.

For pesticides, the oral-inhalation concordance was markedly lower: $24.12 \%$ across 348 substances classified according to GHS criteria (Tab. 5). For an additional $23.85 \%$ of substances, the oral test resulted in a more severe classification, whereas inhalation data led to a more severe classification for $51.72 \%$ of substances examined. Active substances classified as GHS Category 1 via inhalation but unclassified orally include Acequinocyl, Ammonium Thiosulfate, Bifenox, Bromacil, Bupirimate, Buprofezin, Clofencet, Cyflufenamid, Dichlobenil, Diflufenzopyr, Disodium tetraborate, Mesotrione, Metrafenone, Pine Oil, Piperonyl Butoxide, and Sintofen. Further investigation is needed to identify the physico-chemical (reactivity, particle size, vapor pressure, solubility), kinetic, metabolic, and other factors that underlie differences seen in acute toxic responses following oral and inhalation exposure (Pauluhn et al., 1996). It is possible, however, that at least some of the observed
Tab. 4: Concordance among oral and inhalation route acute toxicity classifications for industrial chemicals in the EU New Chemicals Database according to the former EU DSD scheme

\begin{tabular}{lcccl}
\cline { 2 - 5 } & \multicolumn{2}{c}{ ORAL } & & \\
\hline INHALATION & NC & $\mathbf{X n}$ & $\mathbf{T}$ & $\mathbf{T +}$ \\
\hline $\mathbf{N C}$ & 50 & 8 & 0 & 0 \\
\hline $\mathbf{X n}$ & 4 & 1 & 0 & 0 \\
\hline $\mathbf{T}$ & 3 & 1 & 0 & 0 \\
\hline $\mathbf{T}+$ & 2 & 1 & 1 & 0 \\
\hline
\end{tabular}

* $\mathrm{NC}=$ no classification required $; \mathrm{X}=$ harmful; $\mathrm{T}=$ toxic $; \mathrm{T}+=$ very toxic

Tab. 5: Concordance among oral and inhalation route acute toxicity classifications for pesticide active substances according to the GHS (without the optional Category 5)

\begin{tabular}{lccccc}
\cline { 2 - 6 } & ORAL & & & \\
\hline INHALATION & NC & $\mathbf{4}$ & $\mathbf{3}$ & $\mathbf{2}$ & $\mathbf{1}$ \\
\hline NC & 36 & 23 & 17 & 2 & 3 \\
\hline $\mathbf{4}$ & 53 & 38 & 17 & 6 & 8 \\
\hline $\mathbf{3}$ & 29 & 17 & 7 & 4 & 2 \\
\hline $\mathbf{2}$ & 23 & 17 & 7 & 3 & 1 \\
\hline $\mathbf{1}$ & 16 & 11 & 4 & 3 & 0 \\
\hline
\end{tabular}

discordance could be an artifact of the classification system itself. As illustrated in Figure 3, criteria for making acute inhalation classifications differ considerably among countries and sectors. Differences include both the $\mathrm{LC}_{50}$ thresholds that define individual classification categories, as well as the fact that some systems establish separate criteria for aerosols (solid and liquid) versus vapors and gases while others do not. For example, the $\mathrm{LC}_{50}$ dose range for an inhalation Category 1 classification under the US pesticides scheme is quite narrow, i.e., up to $0.05 \mathrm{mg} / \mathrm{l}$ for all substances, regardless of their physical state. The same range is used under the GHS for dusts and mists; however, for vapors the upper threshold for a Category 1 classification is tenfold higher, i.e., $0.5 \mathrm{mg} / \mathrm{l}$, whereas the US pesticides scheme has established this dose level as the upper threshold for a Category II classification. Similarly, the dose range for a GHS Category 2 classification for vapors is identical to the US pesticide Category III, while vapors classified as Category IV under the US scheme would be classified as Category 3 under the GHS. Differences of comparable magnitude also would be evident if GHS classifications were compared against those of the former EU DSD scheme. Thus, depending on the classification scheme used, physical state of the substance in question and whether it is deemed to be predominantly mist or vapor over the course of a test, acute inhalation classifications could easily diverge by at least one severity category among GHS, 
DSD and EPA pesticide schemes. Additionally, there appears to be an inherent bias toward more severe classifications via the inhalation route, particularly under the GHS, which could provide some explanation for the low oral-inhalation concordance seen for pesticides.

From a regulatory perspective, $\mathrm{REACH}$ requires that all substances produced or marketed in the $\geq 10$ tpa range in Europe must possess acute toxicity data for two exposure routes. Assuming that all or most dermal route testing could be waived, inhalation would become the new default second route by process of elimination. However, in light of the reasonably high oralinhalation concordance and sensitivity of the oral test for chemicals $(83.1 \%$ when taken together), albeit across a limited data set, there may be value in exploring whether opportunities exist for expansion or refinement of existing criteria for waiving an inhalation study requirement under REACH (OJ, 2007; ECHA, 2008) and other international chemical regulatory schemes. Criteria currently specified in REACH technical guidance include knowledge of local toxicity, low volatility (i.e., vapor pressures $<1 \times 10^{-5}$ and $<1 \times 10^{-4}$ for indoor and outdoor uses, respectively), molecular weight, particle size (particles larger than $100 \mu \mathrm{m}$ are less likely to be inhalable), mass median aerodynamic diameter, water solubility, reactivity, and ability to generate a stable test atmosphere (ECHA, 2008; Pauluhn et al., 1996). Waiving would not be envisioned in the case of highly acutely toxic substances for which derivation of an acute DNEL or AEGL is necessary. It may also be prudent to re-examine classification criteria for acute inhalation toxicity (i.e., $\mathrm{LC}_{50}$ cut-offs between categories) to verify the consistency of severity categories across exposure routes (e.g., that the severity of effects seen in an inhalation Category 2 are reasonably comparable to those of oral or dermal classifications of the same magnitude).

\section{Conclusions and recommendations}

Our analysis provides further, compelling evidence that dermal acute systemic toxicity data almost never drive regulatory classification and labeling decisions in the chemicals, agrochemicals, or biocides sectors. Thus, their contribution to the protection of consumers and workers would appear to be marginal at best and insufficient to warrant the routine conduct of redundant, lethal in vivo studies. We therefore recommend the following:

1. Dermal acute systemic testing should not be required for substances that are non-classified by the oral route, since the data clearly show that the oral route is almost always more sensitive, and the concordance among oral and dermal routes for non-classified substances is $100 \%$ for industrial and agrochemicals and $99.4 \%$ for biocides. Relevant national/regional data requirements for all three classes of substances should be revised accordingly (i.e., deleted or downgraded to conditional requirements) together with applicable implementing guidance.

2. Before a new dermal acute toxicity study is carried out, an in vitro dermal absorption/penetration study (OECD, 2004) should be conducted to assess the likely magnitude and rate of dermal bioavailability.
3. Data requirements prescribing acute dermal systemic testing of formulated agrochemical and biocidal products and wellcharacterized mixtures should be reconsidered in light of data presented and the established and conservative practice of classification by calculation.

4. It is important to avoid the situation under REACH whereby inhalation becomes the default second route for acute testing for substances in the $\geq 10$ tpa tonnage band (by process of elimination if dermal testing is discontinued). Opportunities for refinement or expansion of existing criteria for adaptation or waiving of acute inhalation study requirements for chemicals should be fully explored.

5. Further investigation is needed to identify the physicochemical, kinetic, metabolic, and other factors that underlie differences seen in acute toxic responses following oral and inhalation exposure.

\section{References}

Balls, M. (1991). Why modification of the LD50 will not be enough. Lab. Anim. 25, 198-206.

CPSC - United States Consumer Product Safety Commission (1973). Federal Hazardous Substances Act implementing regulations, 16 CFR $\$ 1500.3$. Washington, DC: US Government.

Creton, S., Dewhurst, I. C., Earl, L. K. et al. (2010). Acute toxicity testing of chemicals: opportunities to avoid redundant testing and use alternative approaches. Crit. Rev. Toxicol. 40, 50-83.

EC - European Commission (2007). Annex to the fifth report on the statistics on the number of animals used for experimental and other scientific purposes in the Member States of the European Union. Brussels: European Commission, 277 pp.

EC (2009a). Working Documents of the Standing Committee on the Food Chain and Animal Health in view of the inclusion of plant protection active substances in Annex I of Directive 91/414/EEC. http://ec.europa.eu/sanco_pesticides/public/index.cfm (accessed 06.06.2010).

EC (2009b). Assessment Reports regarding inclusion of active substances in Annex I or IA to Directive 98/8/EC. http:// ecb.jrc.ec.europa.eu/esis/index.php?PGM=bpd (accessed 06.06.10).

ECHA - European Chemicals Agency (2008). Guidance on information requirements and chemical safety assessment. Chapter R.71: Endpoint specific guidance (291-310). Helsinki, Finland: ECHA.

EFSA - European Food Safety Authority (2009). Rapporteur Member State assessment reports submitted for the EU peer review of active substances used in plant protection products. Parma, Italy: EFSA. http://dar.efsa.europa.eu/dar-web/provision (accessed 06.06.10).

EPA - United States Environmental Protection Agency (2004). Chemical hazard classification and labeling: comparison of OPP requirements and the GHS. Washington, DC: US EPA. http://www.epa.gov/oppfead1/international/global/ghscriteria-summary.pdf (accessed 06.06.10).

EPA (2007). Label Review Manual, Chapter 7: Precautionary 
Statements. Washington, DC: US EPA. http://www.epa.gov/ oppfead1/labeling/lrm/chap-07.pdf (accessed 06.06.10).

EPA (2009). Fact sheets on new active ingredients. Washington, DC: US EPA. http://www.epa.gov/opprd001/factsheets (accessed 06.06.10).

EPA (2010). Pesticide reregistration status and decision documents. Washington, DC: US EPA. http://www.epa.gov/pesticides/reregistration/status.htm (accessed 06.06.10).

ICH - International Conference on Harmonization of Technical Requirements for Registration of Pharmaceuticals for Human Use (2009). Guidance on nonclinical safety studies for the conduct of human clinical trials and marketing authorization for pharmaceuticals - M3(R2). http://www.ich.org/fileadmin/ Public_Web_Site/ICH_Products/Guidelines/Safety/M3_R2/ Step4/M3_R2_Guideline.pdf (accessed 06.06.10).

Indans, I., Fry, T., Parsons, P. et al. (1998). Classification and labelling of new industrial chemicals for acute toxicity, skin and eye irritation (abstract). In: Proceedings of the British Toxicology Society Annual Congress, University of Surrey, Guildford, 19-22 April 1998. Hum. Exp. Toxicol. 17, 469534.

IPCS - International Programme on Chemical Safety (2009). INCHEM database. http://www.inchem.org (accessed 06.06.10).

OECD - Organization for Economic Co-operation and Development (2004). OECD Guideline for the testing of chemicals No. 428 - Skin absorption: in vitro method. Paris, France: OECD, 8 pp.

OECD (2009). OECD Guidelines for the testing of chemicals. Section 4: health effects. Paris: OECD. http://www.oecd.org/ env/testguidelines (accessed 06.06.10).

OJ - Official Journal of the European Communities (1967). Council Directive 67/548/EEC of 27 June 1967 on the approximation of laws, regulations and administrative provisions relating to the classification, packaging and labeling of dangerous substances (1-98). Brussels: European Union.

OJ (1986). Council Directive 86/609/EEC of 24 November 1986 on the approximation of laws, regulations and administrative provisions of the Member States regarding the protection of animals used for experimental and other scientific purposes (1-28). Brussels: European Union.

OJ (1999). Directive 1999/45/EC of the European Parliament and of the Council of 31 May 1999 concerning the approximation of the laws, regulations and administrative provisions of the Member States relating to the classification, packaging and labeling of dangerous preparations (1-68). Brussels: European Union.

OJ (2007). Regulation (EC) No. 1907/2006 of the European Parliament and of the Council concerning the Registration, Evaluation, Authorization and Restriction of Chemicals (REACH) (1-849). Brussels: European Union.
OJ (2008). Regulation (EC) No. 1272/2008 of the European Parliament and of the Council on classification, labelling and packaging of substances and mixtures (1-355). Brussels: European Union.

OSHA - United States Occupational Safety and Health Administration (2009). Hazard communication; proposed rule (50280-50549). Washington, DC: Federal Register.

Pauluhn, J., Bury, D., Föst, U. et al. (1996). Acute inhalation toxicity testing: considerations and regulatory aspects. Arch. Toxicol. 71, 1-10.

Robinson, S., Delongeas, J.-L., Donald, E. et al. (2008). A European pharmaceutical company initiative challenging the regulatory requirement for acute toxicity studies in pharmaceutical drug development. Regul. Toxicol. Pharmacol. 50, 345-352.

Russell, W. M. S. and Burch, R. L. (1959). The principles of humane experimental technique. London: Methuen \& Co. Ltd. (Reissued: 1992, Universities Federation for Animal Welfare, Herts, England).

Seidle, T., Robinson, S., Holmes, T. et al. (2010). Cross-sector review of drivers and available 3 Rs approaches for acute systemic toxicity testing. Tox. Sci. 16, 382-396.

Thomas, H. D. and Dewhurst, I. C. (2007). What does a dermal acute toxicity study add to the information on a plant protection pesticide? Toxicol. 231, 104-119.

Trevan, J. W. (1927). The error of determination of toxicity. Proc. R. Soc. Lond. 1.1B, 483.

UN - United Nations (2007). Globally harmonized system of classification and labeling of chemicals. New York: United Nations.

\section{Acknowledgements}

The authors acknowledge members of the European Partnership for Alternative Approaches to Animal Testing (EPAA) Acute Toxicity Task Force for their advice. This work was supported by the authors' affiliated institutions, together with a grant for the lead author from the Doerenkamp-Zbinden Foundation, Switzerland. In addition, we would like to thank Joaquin Baraibar Fentanes from the System Toxicology Unit (IHCP, JRC, Ispra), who helped with data retrieval from the NCD

\section{Correspondence to}

Troy Seidle

Humane Society International

Research \& Toxicology Department

5 Underwood Street (Robinsons Suite)

London N1 7LY, UK

Phone: +32 491317072

e-mail: tseidle@hsi.org 